J. Clin. Chem. Clin. Biochem.

Vol. 20, 1982, pp. 921-927

\title{
Ermittlung der katalytischen Aktivität der Lipase im Serum durch Messung bzw. Schätzung des pH-Abfalls in einer Triolein-Emulsion
}

\author{
Von M. Hockeborn und W. Rick \\ Institut für Klinische Chemie und Laboratoriumsdiagnostik der Universität Düsseldorf
}

(Eingegangen am 2. März/9. August 1982)

\begin{abstract}
Zusammenfassung: Bei der enzymatischen Hydrolyse von Triolein durch die Lipase im Serum entstehen Wasserstoffionen, die zu einem pH-Abfall im Testansatz führen. Das Ausmaß der pH-Änderung ist abhängig von der katalytischen Aktivität der Lipase und von der Pufferkapazität des Testsystems. In dem beschriebenen Verfahren zur Bestimmung der katalytischen Aktivität der Lipase im Serum dient der potentiometrisch gemessene und registrierte pH-Abfall als Meßgröße. Vergleichsuntersuchungen ergaben eine befriedigende Ubereinstimmung der Ergebnisse mit den Resultaten des kontinuierlichen titrimetrischen Tests. Weitere Untersuchungen wurden mit einer Modifikation des von Härtel et al. ((1971), Z. Klin. Chem. Klin. Biochem. 9, 396-397) beschriebenen Suchtests ausgefuihrt, der auf der Schätzung des pH-Abfalls mittels Farbänderung eines Indikators beruht. Bei ausrieichender Erfahrung des Untersuchers ist auch dieser Test zur reproduzierbaren Ermittlung der katalytischen Aktivität der Lipase im Serum geeignet.
\end{abstract}

\section{Determination of the catalytic activity of lipase in serum by measurement or estimation of the $\mathrm{pH}$ decrease in a triolein emulsion}

Summary: In the enzymic hydrolysis of triolein by lipase in serum, hydrogen ions are produced which lead to a decrease in the $\mathrm{pH}$ of the test system. The extent of this $\mathrm{pH}$ change depends on the catalytic activity of the lipase and on the buffering capacity of the test system. In the method described for the determination of the catalytic activity of lipase in serum, the decrease in $\mathrm{pH}$ is measured and recorded potentiometrically. Comparative studies showed a satisfactory correlation of results with those from the continuous titrimetric method. Further studies were performed with a modification of the detection method described by Härtel et al. ((1971) Z. Klin. Chem. Klin. Biochem. 9, 396-397), based on the estimation of the $\mathrm{pH}$ decrease from the colour change of an indicator. With operator experience, this test also gives reproducible results for the catalytic activity of lipase in serum.

\section{Einführung}

Zur Bestimmung der katalytiṣchen Aktivität der Pankreaslipase (Triacylglycerol acyl hydrolase, EC 3.1.1.3) im kontinuierlichen titrimetrischen Test (2) sind ein $\mathrm{pH}$ Meter, eine Motorbürette und ein empfindliches Regelgerät, das eine Konstanthaltung des $\mathrm{pH}$ :Werts im Testansatz in einem Bereich von $\pm 0,001 \mathrm{pH}$-Einheiten gestattet, erforderlich. Da die enzymatische Hydrolyse des als Substrat verwendeten Trioleins unter den beschriebenen Bedingungen ein relativ breites pH-Optimum aufweist, ist es auch möglich, die Lipaseaktivität im Serum ohne Titrationseinirichtung aufgrund der $\mathrm{pH}$-Änderung, die im Testsystem durch die freigesetzten Wasserstoffionen bewirkt wird, zu ermitteln. Eine quantitative Aussage ist durch kontinuierliche Messung des pH-Abfalls zwischen pH 9,0 und 8,5 möglich. Zum anderen, kann die Lipaseaktivität $\mathrm{zwischen} \mathrm{pH}$-Werten von etwa 8,3 und 7,4 an der Farbänderung eines Indikators ( $m$-Kresolpurpur) durch Vergleich mit einer empirisch erstellten Farbskala abgeschätzt werden (1).

\section{Material}

Kontinuierliche Registrierung des pH-Abfalls Reagentien

$\mathrm{Zu}$ den Untersuchungen wurden die für den kontinuierlichen titrimetrischen Test verwendeten und bereits 1969,1976 bzw. 1982 beschriebenen Reagentien verwendet $(2,3,4)$ :

1. Gummi arabicum-Lösung, $100 \mathrm{~g} / 1$ in bidest. Wasser (2).

2. Triolein-Emulsion, $0,21 / 1$ in Lösung 1 (2), pH-Wert mit Natronlauge auf etwa 9,4 einstellen.

3. Natriumglykocholatlösung, $75 \mathrm{mmol} / 1$ in bidest. Wasser (3).

4. Natronlauge, $100 \mathrm{mmol} / 1$.

5. Salzsäure, $100 \mathrm{mmol} / \mathrm{l}$.

6. Präzisionspuffer Radiometer $S 1510$, bei $25^{\circ} \mathrm{C} \mathrm{pH} \mathrm{7,410.}$

7. Präzisionspuffer Radiometer $\mathrm{S} 1500$, bei $25^{\circ} \mathrm{C} \mathrm{pH} 6,865$.

8. Phosphatpuffer-Lösung, pH 6,88, $25 \mathrm{mmol} / 1$, Merck 7254.

9. Acetatpuffer-Lösung, pH 4,66, $100 \mathrm{mmol} / \mathrm{l}$, Merck 7827.

10. Stickstoff, frei von Kohlendioxid. 


\section{Meßanordnung}

1. Digital-pH-Meter PHM 64, Radiometer Deutschland.

2. Elektronischer Schreiber Servograph REC 80 mit TitrigraphModul REA 160, Radiometer Deutschland.

3. Glaselektrode G 202 C, Kalomelelektrode K 4112, Radiometer Deutschland.

4. Kunststoffspitze zur Stickstoffzufuhr, Radiometer Deutschland.

5. Halterung der Elektroden und Kunststoffspitze durch den Elektrodenkopf der Mikro-Titrationseinrichtung TTA 31, Radiometer Deutschland.

6. Magnetrührer und Magnetstäbchen (etwa $25 \mathrm{~mm}$ Länge und $9 \mathrm{~mm}$ Durchmesser).

7. 25 ml-Bechergläser mit passendem Temperiermantel aus Kupfer, der mittels Thermostat auf $25^{\circ} \mathrm{C}$ gehalten wird.

\section{Probenmaterial}

Bei den verwendeten Proben handelte es sich um:

Seren von Gesunden,

Seren von Patienten mit akuten oder chronischen Pankreaserkrankungen,

Seren, in denen die Pankreaslipase durch zweistündige Inkubation bei $56^{\circ} \mathrm{C}$ vollständig inaktiviert worden war, wie im kontinuierlichen titrimetrischen Test mit Triolein als Substrat nachgewiesen wurde,

Kontrollseren.

\section{Schätzung des pH-Abfalls}

\section{Reagentien}

11. $m$-Kresolpurpur-Lösung, $12,5 \mathrm{~g} / 1$ in $50 \mathrm{mmol} / 1$ Natronlauge. Da der Farbton der Substanz sich von Charge zu Charge geringfügig unterscheiden kann, empfiehlt es sich, die Indikatorlösung aus der Testpackung Merckognost Lipase (Merck 11000) zu benutzen. Die darin enthaltene Farblösung wird nach Angaben des Herstellers (5) jeweils auf ausreichende Übereinstimmung mit der beigefügten Skala geprüft.

12. Indikator- und Gallensalz-haltige Triolein-Emulsion: $100 \mathrm{ml}$ Triolein-Emulsion (Reagens 2), $10 \mathrm{ml}$ Indikatorlösung (Reagens 11) und 1,2 $\mathrm{ml}$ Natriumglykocholatlösung (Reagens 3) werden gemischt.

Die Substratemulsion muß eine violett-rötliche Farbe zeigen, bei zu intensiver Violettfärbung bzw. Braun- bis Gelbfärbung ist der erforderliche Farbton durch Zugabe kleiner Volumina Salzsäure oder Natronlauge einzustellen.

\section{Probenmaterial}

s.o.

\section{Methodik}

Kontinuierliche Registrierung des pH-Abfalls

\section{Prinzip}

Die bei der enzymatischen Hydrolyse von Triolein entstehenden Wasserstoffionen führen in dem schwach gepufferten Testsystem zu einem pH-Abfall, der $\mathrm{zwischen}$ pH 9,0 und 8,5 mittels pHMeter und angeschlossenem Registriergerät aufgezeichnet wird.

\section{Ausfüihrung}

Zur Kalibrierung des pH-Meters werden die unter Reagentien 6-9 aufgeführten und auf $25^{\circ} \mathrm{C}$ temperierten Pufferlösungen verwendet. Die Schreiberspreizung wird auf $\mathrm{pH} 8,4-9,1$ $(=25 \mathrm{~cm}$ ) eingestellt, der Papiervorschub erfolgt $\mathrm{mit} 1 \mathrm{~cm} / \mathrm{min}$, bei sehr hohen kataly tischen Aktivitäten mit $6 \mathrm{~cm} / \mathrm{min}$.

Die Meßtemperatur beträgt $25^{\circ} \mathrm{C}$.
Zur Ausführung der Bestimmungen mischt man in 25 ml-Bechergläsern: 10,0 ml Triolein-Emulsion (Reagens 2)., ca. pH 9,4, $3,85 \mathrm{ml}$ bidest. Wasser,

$150 \mu 1$ Natriumglykocholatlösung (Reagens 3),

nach Temperierung auf $25^{\circ} \mathrm{C}$ wird

$1,0 \mathrm{ml}$ Serum (bzw. Serumverdünnung in inaktiviertem Sammelserum) zugesetzt.

Um Störungen durch das Kohlendioxid der Raumluft zu vermeiden, durchströmt man dẹn Raum über dem Testansatz mit Kohlendioxid-freiem Stickstoff.

Der pH-Wert des Ansatzes soll etwa 9,1 betragen, bei größeren Abweichungen ist das $\mathrm{pH}$ durch Zugabe geringer Volumina $100 \mathrm{mmol} / 1$ Natronlaug̃e bzw. Salzsäure in diesen Bereich żu bringen. Ist der $\mathrm{pH}$-Wert auf etwa 9;0 abgefallen, beginnt man mit der Registrierung. Je nach katalytischer Aktivität der Lipase

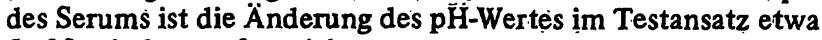
5-20 min lang aufzuzeichnen.

Da die Berechnung der katalytischen Aktivität des Enzyms im analy sierten Serum über die Pufferkapazität der Reaktionsmischung erfolgt, empfiehlt es sich, die pH-Änderung im Bereich zwischen pH 9,0 und 8,5 nach Zugabe eines definierten Volumens Salzsäure (100 mmol/l $)$ zu messen bzw. zu registrierẹn (s. Ergebnisse).

\section{Auswertung}

Zwischen pH-Werten von 9,0 und 8,5 erfolgt die Zunahme der Wasserstoffionen-Konzentration im Testansatz geradlinig. Aus dem registrierten $\mathrm{pH}-\mathrm{Ab}$ fall wird durch Parallelverschiebung das durchschnittliche $\Delta \mathrm{pH} / \mathrm{min}$ ermittelt.

\section{Berechnung}

Aufgrund der Pufferkapazität eines Testarisatżes, der $1,0 \mathrm{ml}$ inaktiviertes Sammelserum enthält $\left(=1,60 \pm 0,05 \mu \mathrm{mol} \mathrm{H} \mathrm{H}^{+}\right.$fur ein $\Delta \mathrm{pH}$ von 0,100 ) wird die katalytische Aktivität der Lipase in Seren wie folgt berechnet:

Katalytische Aktivität $=\Delta \mathrm{pH} / \mathrm{min} \cdot 16000\left(\mathrm{U} / 1\left(25^{\circ} \mathrm{C}\right)\right)$

\section{Schätzung des pH-Abfalls}

Prinzip

Versetzt man die Triolein-Emulsion mit $m$-Kresolpurpurlösung, so kann der nach Serumzugabe durch die entstehenden Wasserstoffionen bedingte $\mathrm{pH}$-Abfall an der Farbänderung des Indikators $\mathrm{zwischen}$ pH-Werten von etwa 8,3 bis 7,4 verfolgt und somit die katalytische Aktivität der Lipase im Serum abgeschätzt werden.

\section{Ausführung}

In Einmälröhrchen werden pipettiert:

2,0 ml Indikator- und Gallensalz-haltige Triolein-Emulsion $+200 \mu \mathrm{l}$ Serum,

die Ansätze sind mittels Vortex- oder Whirl-Mix o.ä. sorgfältig zu mischen. Weicht die Farbe einzelner Bestimmungsansätze aufgrund der unterschiedlichen pH-Werte der Seren von dem mit „Null bis 60 " bezeichneten Bereich ab, so wird die Färbung · durch Zugabe sehr geringer Volumina $100 \mathrm{mmol} / 1$ Säure oder Lauge in den genannten Skalenabschnitt gebracht. Die Röhrchen werden in einem Wasserbad bei $25^{\circ} \mathrm{C}$ inkubiert.

Einige Minuten nach Mischen der Ansätže vergleicht man deren Farbton mit der kalibrierten Farbskala und notiert den entsprechenden Wert. Die Ablesung wird bei Seren mit geringer katalytischer Aktivität nach $30,60,90$ und 120 Minuten wiederholt. Bei hochaktiven Proben wird in kürzeren Abständen - evtl: minutenweise - ausgewertet.

Da der Testansatz an der Oberfläche durch das Kohlendioxid der Raumluft in Richtung. gelber Farbtöne verändert wird, ist ein Umschütteln der Röhrchen während der Inkubation und Ablesung streng żu vermeiden, da dies zu fälșchlich erhöhten Aktivitäten führt. 


\section{Berechnung}

Bei korrekter Ausführung ergeben sich unter Berïcksichtigung der nur stufenweise (20 U/1) möglichen Auswertung annähernd konstante Differenzwerte zwischen den Ablesungen zu den genannten Zeiten (s. Abb. 1). Die Farbskala ist für eine Inkubationszeit von 2 Stunden ausgelegt. Die ermittelte Differenz $z$ wischen dem Farbvergleich zur Zeit $t=0$ min und demjenigen zur Zeit $t=120$ min entspricht der katalytischen Aktivität der Lipase im untersuchten Serum in $\mathrm{U} / 1\left(25^{\circ} \mathrm{C}\right)$.

Hochaktive Seren führen zu einer schnellen Änderung der Farbe des Indikators und erfordern somit eine Ablesung in kurzen Zeitabständen. Dementsprechend muß eine Korrektur auf eine Inkubationszeit von 2 Stunden erfolgen.

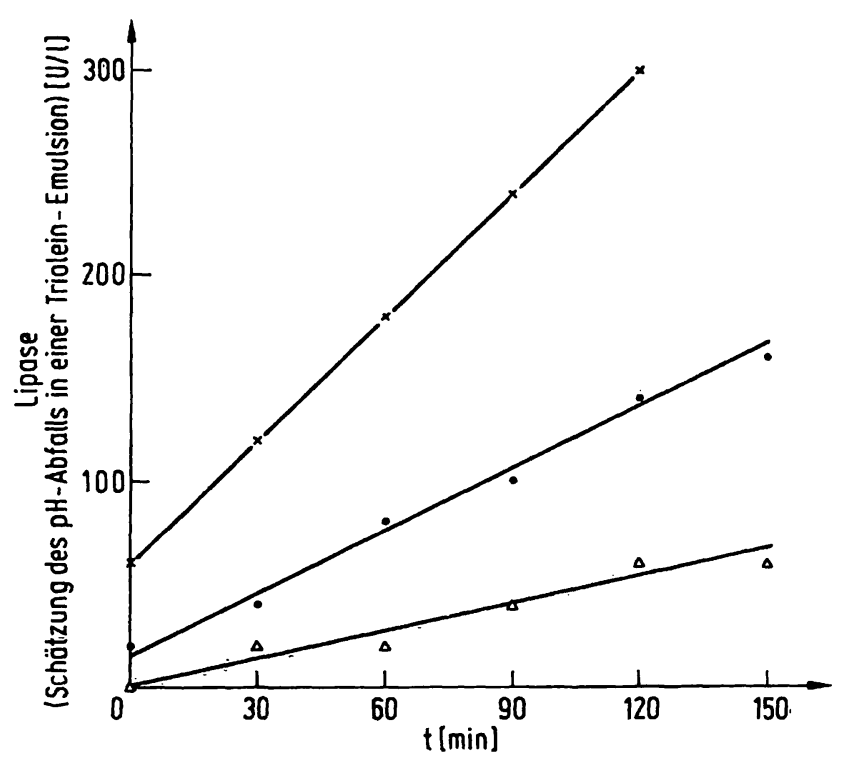

Abb. 1. Ermittlung der kataly tischen Aktivität der Lipase im Serum durch Schätzung des pH-Abfalls (modif. nach Härtel et al. (1)).

Ablesungen an der Farbskala nach unterschiedlich langer Inkubation des Testansatzes.

$\triangle \longrightarrow \Delta$ Serum Nr. 105

- - Serum Nr. 12

$x-x$ Serum Nr. 22

\section{Ergebnisse}

\section{Kontinuierliche Regiștrierung des $\mathrm{pH}-\mathrm{Ab}$ falls}

\section{Reagentien-Leerwert}

Unter den beschriebenen Bedingungen, d.h. bei Verdrängung des Kohlendioxids der Raumulut über dem Testansatz durch Stickstoffzufuhr, fanden wir sowohl in Abwesenheit als auch nach Zusatz von inaktiviertem Sammelserum keine pH-Änderung in der Reaktionsmischung. Wird mit einem zu großen Volumen $\mathrm{N}_{2}$ durchströmt, kommt es infolge der Austreibung von $\mathrm{CO}_{2}$ aus dem Testansatz zu einem geringfugigen Anstieg des pH-Wertes. Die erforderliche optimale Stickstoffzufuhr ist daher an Leerwerten zu kontrollieren.

\section{Testbedingungen}

Wir führten die Messungen unter den in früheren Arbeiten als optimal ermittelten Konzentrationen der Reak- tionspartner aus (4). Versuche, die Empfindlichkeit des Verfahrens dadurch zu steigern, daß die Konzentration an Gummi arabicum in der Substratemulsion auf 50 bzw. $20 \mathrm{~g} / 1$ herabgesetzt wurde, schlugen fehl. Zum einen ergaben sich aufgrund der verminderten Pufferung stärkere Schwankungen in der pH-Anzeige und damit der Registrierung, andererseits kam ès bei Konzentrationen an Gummi arabicum unter $50 \mathrm{~g} / 1 \mathrm{zu}$ einer Entmischung der Substratemulsion. Setzt man Serum mit einer katalytischen Aktivität der Lipase von $60 \mathrm{U} / 1$ in den hier beschriebenen Test ein, so findet man ein $\Delta \mathrm{pH}$ von 0,0375/10 min. Eine Probe mit $160 \mathrm{U} / 1$ (obere Grenze des Normbereichs) ergibt ein $\Delta \mathrm{pH}$ von $0,100 / 10 \mathrm{~min}$. Somit ist die Empfindlichkeit des Verfahrens als ausreichend zu bezeichnen.

\section{Reaktionsablauf}

Der pH-Abfall im Testansatz erfolgt - unabhängig von der eingesetzten katalytischen Aktivität - zwischen pH-Werten von 9,0 und 8,5 geradlinig. Als Beispiel ist der Verlauf bei Einsatz eines Serums mit einer katalytischen Aktivität von $1500 \mathrm{U} / \mathrm{l}$ dargestellt (Abb. 2).

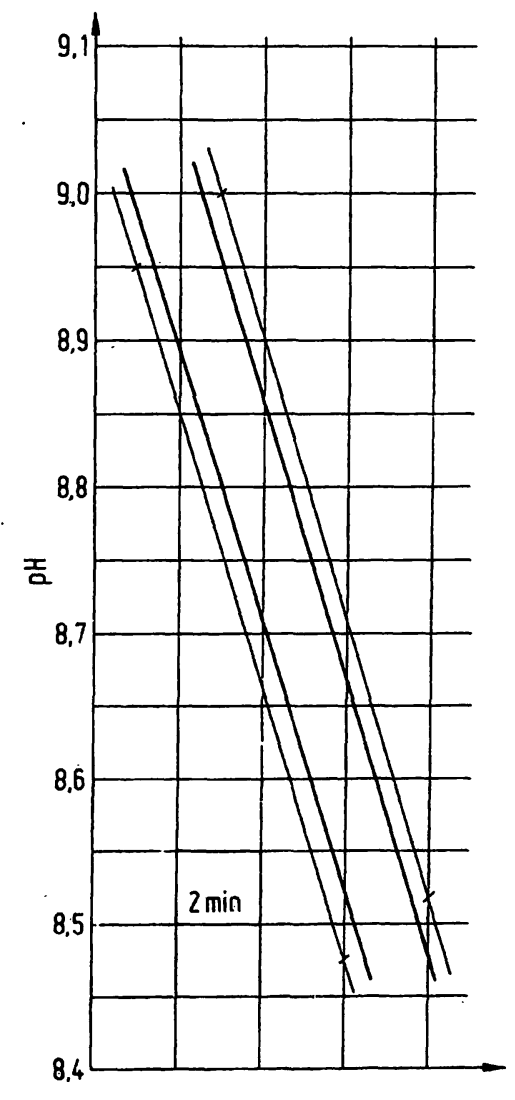

Abb. 2. Ermittlung der kataly tischen Aktivität der Lipase im Serum durch potentiome trische Messung des $\mathrm{pH}$ Abfalls im Testansatz.

Reaktionsablauf in Abhängigkeit von der Zeit. Einsatz eines Serums mit $\bar{x}=1500$ U/1 (kontinuierlicher titrimetrischer Test).

Auswertung der Registrierungen (Doppelbestimmung) mittels Parallelverschiebung und Berechnung des $\Delta \mathrm{pH} / 5$ min; gefundene katalytische Aktivität $=1540$. $1515 \mathrm{U} / 1$. 


\section{Pufferkapazität des Testansatzes}

Durch Zugabe von Salzsäure (100 mmol/l) zu Testen, die $1,0 \mathrm{ml}$ inaktiviertes Sammelserum enthielten, wurde die Pufferkapazität im Ansatz ermittelt. Für einen pH-Abfall um 0,100 waren im Meßbereich zwischen $\mathrm{pH} 9,0$ und $8,51,60 \pm 0,05 \mu \mathrm{mol}$ Wasserstoffionen erforderlich. Aus diesen Ergebnissen wurde der oben angegebene Berechnungsfaktor ermittelt.

Durch getrennte Titration von Serum und von Substratemulsion konnte nachgewiesen werden, daß die Pufferkapazität des Testansatzes zu etwa gleichen Teilen durch Serum und Substrat bedingt ist (s. Diskussion).

Die Puffereigenschaften des Systems bei Einsatz verschiedener Serumproben lassen sich im einzelnen Test

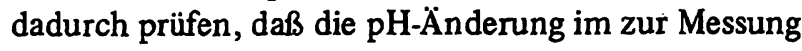
verwendeten $\mathrm{pH}$-Bereich durch Zusatz von $2 \mu \mathrm{mol}$ Wasserstoffionen in Form von Salzsäure (100 mmol/l) gemessen wird. Sie betrug bei 18 untersuchten Seren, deren Proteingehalt zwischen 60 und $80 \mathrm{~g} / 1 \mathrm{lag}, 0,125 \pm$ 0,010 .

\section{Abhängigkeit des Meßsignals von der eingesetzten katalytischen Aktivität}

Seren mit unterschiedlich hoher katalytischer Áktivität wurden mit inakțiviertem Sammelserum im Verhältnis $1+9,1+4$ bzw. $1+1$ verdünnt; $1,0 \mathrm{ml}$ der Verdünnungen wurde in den Test eingesetzt.

Unter den beschriebenen Bedingungen ergab sich eine geradlinige Beziehung zwischen Enzymmenge im Test und pH-Abfall pro Zeiteinheit (Abb. 3). Da die Pufferkapazität des Testansatzes etwa konstant gehalten wer-

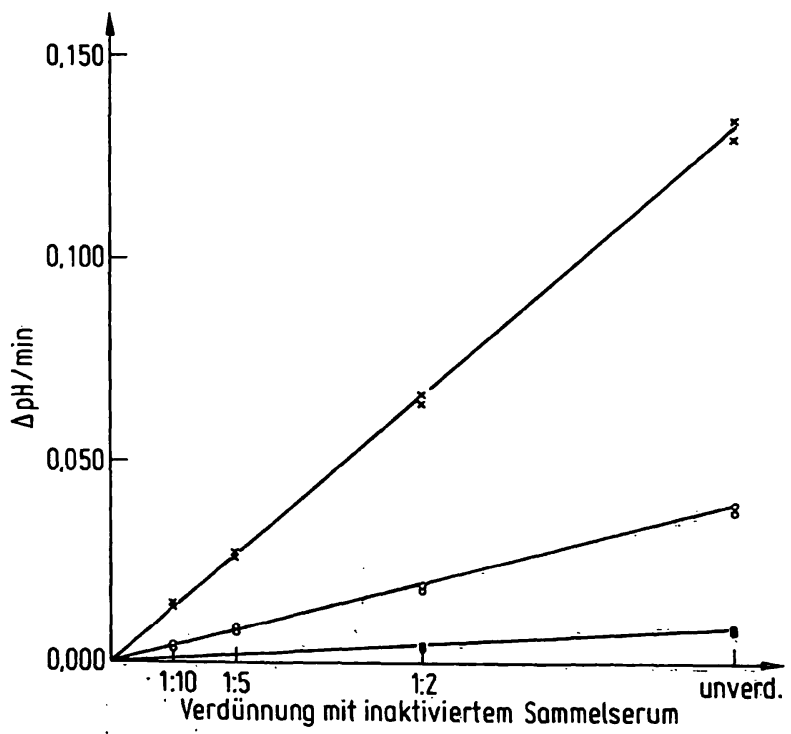

Abb. 3. Ermittlung der katalytischen Aktivität der Lipase im Serum durch potentiometrische Messung des $\mathrm{pH}-$ Abfalls im Testansatz.

Abhängigkeit des Meßsignals von der eingesetzten Enzy maktivität.

Gefundene katalytische Aktivitäten:

$x-x 2130 \mathrm{U} / \mathrm{l}$ (Titration $\dot{\overline{\mathrm{x}}}=2000 \mathrm{U} / \mathrm{l})$

$\circ \longrightarrow 632 \mathrm{U} / 1$ (Titration $\overline{\bar{x}}=660 \mathrm{U} / \mathrm{l}$ )

- $144 \mathrm{U} / \mathrm{l}$ (Titration $\overline{\mathrm{x}}=133 \mathrm{U} / \mathrm{l})$ den muß, ist es selbstverständlich, daß eine Verdünnung des Serums mit physiologischer NaCl-Lösung je nach Volumenverhältnis zu große pH-Änderungen in der Zeiteinheit und somit fälschlich erhöhte katalytische Aktivitäten bewirkt.

\section{Vergleichsuntersuchungen mit dem kontinuierlichen titrimetrischen Test}

An 72 Seren mit einer kätalytischen Aktivität an Lipase zwischen 60 und 2100 U/1 im Titrationșverfahiren wurde die hier beschriebene Methode vergleichend geprüft (Abb. 4). Die Ergebnisse zeigten eine gute Korrelation $(\mathrm{r}=0,990)$. Die Gleichüng der Regressionsgeraden lautete $y=1,04 x-17,7$. Im Wilcoxon-Test ergäben sịch keine signifikanten Differenzen zwischen den Stichproben. Beide Methoden erlauben mithin gleiche diagnostische Aussagen.

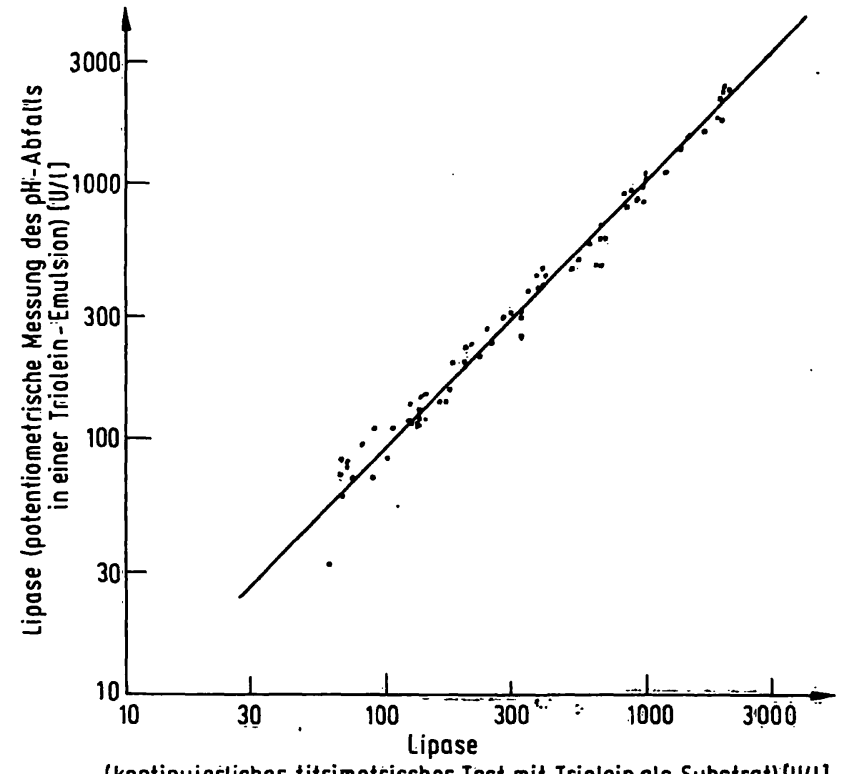

(kontinuierlicher titrimetrischer Test mit Triolein als Substrat):(U/U]

Abb. 4. Vergleich des potentiometrischen Verfahrens mit dem kontinuierlichen titrimetrischen Test an 72 Seren mit einer katalytischen Aktivität an Lipase zwischen 60 und $2100 \mathrm{U} / \mathrm{l}$.

$$
y=1,04 x-17,7
$$$$
\mathrm{I}=0,990
$$

\section{Präzision der potentiometrischen Messung}

Der Variationskoeffizient von Tag zu Tag betrug bei katalytischen Aktivitäten im Bereich um $400 \mathrm{U} / 1$ $\mathrm{VK}=5,9 \%$.

\section{Schätzung des pH-Aḅf̣alls}

\section{Hinweise zur Auswertuing}

Die Schätzung des pḦ-Abfalls mit Hilfe der von Härtel et al. (1) angegebenen Farbskala führt bei ausieichender Ubung des Untersuchers zu reproduzierbaren Ërgebnisssen. Um zwișchen den geringen Farbunterschieden differenżieren żu können, empfiehlt ès sich, zunächst Proben mit bekannter katalytischer Aktivität der Lipase (z. B. Kontrollserenen) zu änälysieren und sich durch häufiges Ablesen in die Farbabstufungen" "einzusehen". 


\section{Untersuchung hochaktiver Seren}

Bei stark erhöhten katalytischen Aktivitäten an Lipase (bis etwa 5000 U/1) ist es möglich, in Minutenabständen abzulesen. Durch Umrechnung entsprechend der Inkubationszeit sind mit diesem Vorgehen zuverlässige Resultate zu erzielen (Abb. 5). Bei extrem hohen katalytischen Aktivitäten sollten die Proben mit inaktiviertem Sammelserum verdünt in den Test eingesetzt werden. Hierdurch ist eine lineare Beziehung zwischen verwendetem Probevolumen und Lipase gewährleistet (Abb. 6).

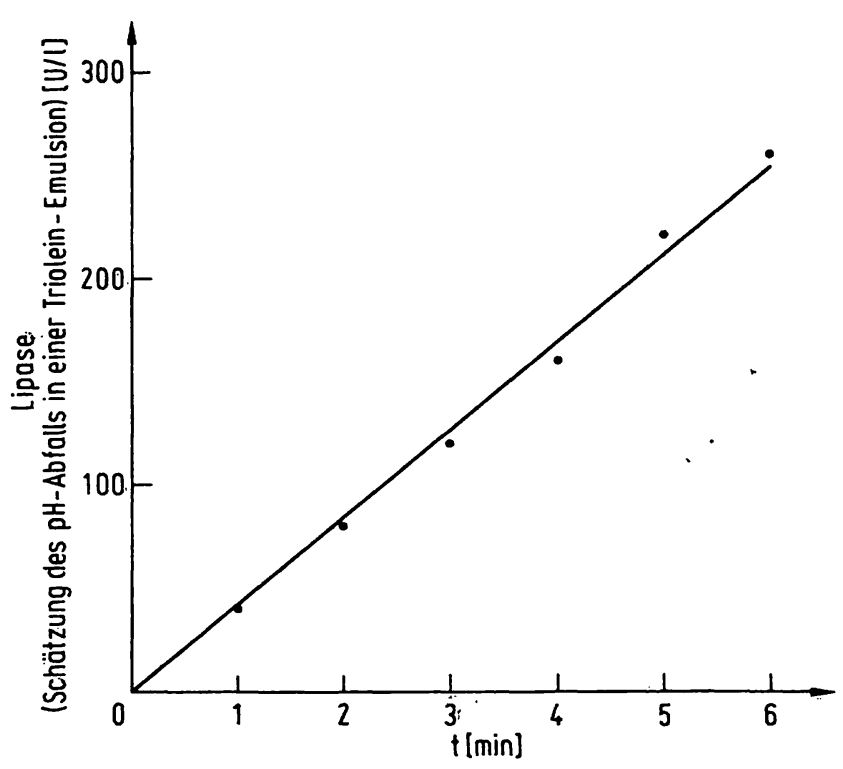

Abb. 5. Ermittlung der kataly tịschen Aktivität der Lipase im Serum durch Schätżung des pH-Abfalls (modif; nach Härtel et al. (1)).

Ablesungen an der Farbskala.nach unterschiedilich langer Inkubation des Tẹstansatzes.

Gefundene katalytische Aktivität:

$5600 \mathrm{U} / \mathrm{l}$ (Titration $\overline{\overline{\mathrm{X}}}=60,00 \mathrm{U} / \mathrm{l}$ )

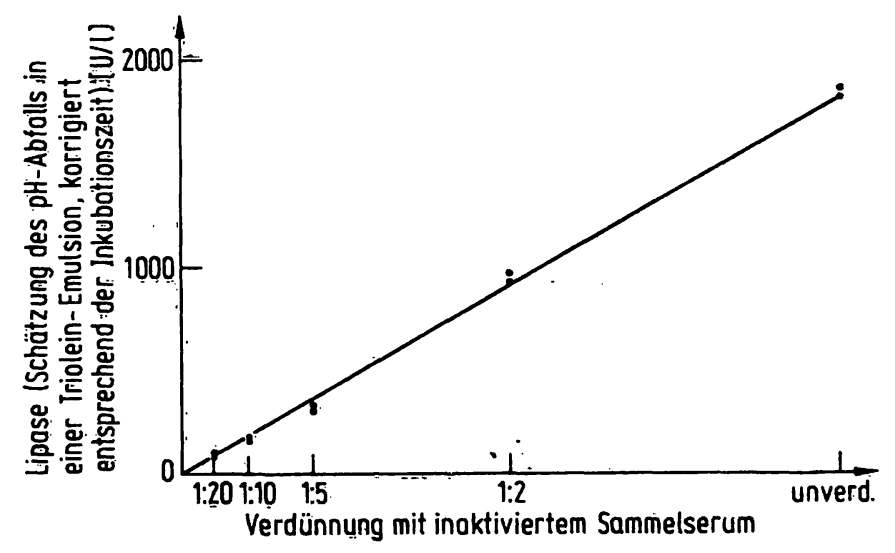

Abb. 6. Ermittlung der katalytischen Aktivität der Lipase im Serum durch Schätzung des pH-Abfalls (modif. nach Härtel et al. (1)).

Einsatz verschiedener Verdünnungen eines hochaktiven Serums. (Aktivität im kontinuierlichen titrimetrischen Test $2000 \mathrm{U} / \mathrm{l}$ ) mit inaktiviertem Sammelserum.

Ablesungen nach unterschiedlich langer Inkubation bei $25^{\circ} \mathrm{C}$.

Gefundene katalytische Aktivität: $1930 \mathrm{U} / 1$
Vergleichsuntersuchungen mit dem kontinuierlichen titrimetrischen Test

An 90 Seren mit katalytischen Aktivitäten bis zu $150 \mathrm{U} / 1(\overline{\mathrm{x}}=83 \mathrm{U} / \mathrm{l})$ ergab sich eine Korrelation von $r=0,816$, die Regressionsgleichung lautete $y=0,73 x+$ 22,4 (Abb. 7). 36 Seren mit erhöhter Lipase ( $\bar{x}=$ $261 \mathrm{U} / 1)$ zeigten eine Korrelation von $\mathrm{r}=0,987$ und eine Regressionsgerade von $y=1,03 x-16,0$.(Abb. 8). Im Wilcoxon-Test fanden sich keine signifikanten Unterschiede zwischen den Stichproben.

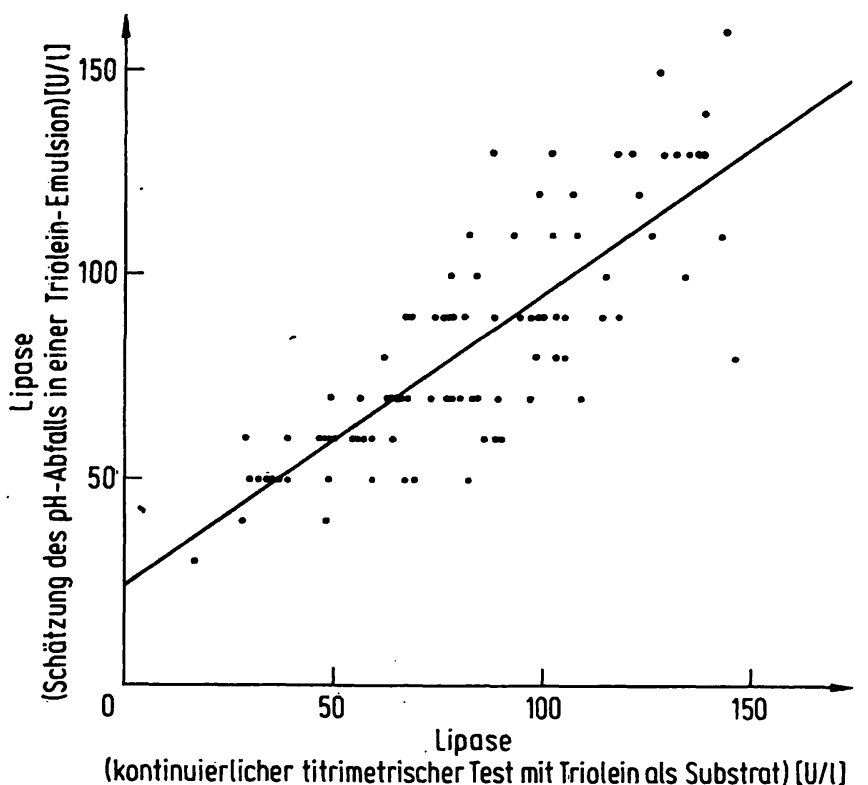

Abb. 7. Vergleich des Verfahrens auf Grund der Schätzung des $\mathrm{pH}-\mathrm{A}$ bfalls mit dem kontinuierlichen titrimetrischen Test an 90 Seren mit einer katalytischen Aktivität an Lipase bis zu $150 \mathrm{U} / 1$.

$y=0,73 x+22,4$ $i=0,816$

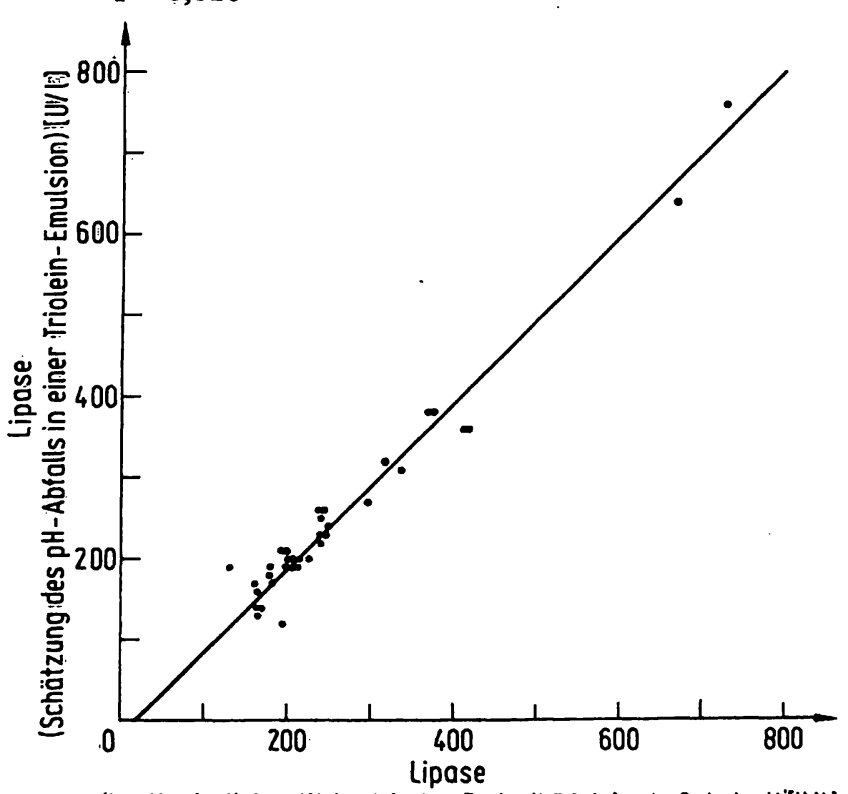

(kontinuierlicher titrimetrischer Test mit Triolein als Substrat)i[U/I]

Abb. 8. Vergleich des Verfahrens auf Grund der Schätzung des pH-Abfalls mit dem kontinuierlichen titrimetrischen Test an 36 Seren mit erhöhter katalytischer Aktivität an Lipase $(\bar{x}=261 \mathrm{U} / \mathrm{l})$.

$y=1,03 x-16,0$

$r=0,987$ 


\section{Präzision des Verfahrens}

Der Variationskoeffizient von Tag zu Tag betrug bei katalytischen Aktivitäten um $300 \mathrm{U} / 1 \mathrm{VK}=6,3 \%$.

\section{Diskussion}

\section{Kontinuierliche Registrierung des $\mathrm{pH}-\mathrm{Ab}$ falls}

Die Ausführung des kontinuierlichen titrimetrischen Tests zur Bestimmung der Lipase $(2,3,4)$ erfordert vièl experimentelles Geschick und eine aufwendige apparative Ausrüstung. Wegen der häufig ungezielten Anordnung von Untersuchungen dürfte es kaum möglich sein, alle anfallenden Proben mit diesem Verfahren zu analysieren.

Durch die hohe Empfindlichkeit der modernen digitalen $\mathrm{pH}-\mathrm{Meter}$ ist es heute möglich, geringe $\mathrm{pH}$-Änderungen reproduzierbar zu messen. Mit diesen Geräten kann die katalytische Aktivität der Lipase des Serums auch dadurch ermittelt werden, daß der $\mathrm{pH}$-Abfall in einem dem titrimetrischen Test entsprechenden Ansatz zwischen $\mathrm{pH} 9,0$ und 8,5 kontinuierlich gemessen und registriert wird. Steht kein Schreiber zur Verfugung, so können die pH-Änderungen des Ansatzes in bestimmten Zeitintervallen mit der Stoppuhr abgelesen werden. Wichtige experimentelle Einzelheiten zu einem derartigen Verfahren wurden von Chance \& Nishimura (6) mitgeteilt. Die Berechnung der katalytischen Aktivität des Enzyms erfolgt nach Angaben der Autoren über die gemessene Pufferkapazität des Testsystems. Die Pufferung des gesamten Ansatzes bei Zusatz von inaktiviertem Sammelserum errechnete sich nach unseren Üntersuchungen zu $1,60 \pm 0,05 \mu \mathrm{mol} \mathrm{H}{ }^{+}$pro $\Delta \mathrm{pH}$ von $0,100(\mathrm{Meß}$ bereich pH 9,0-8,5). Die von uns an Sammelserum ermittelte Pufferkapazität betrug $0,75 \pm 0,02 \mu \mathrm{mol}$ Wasserstoffionen für einen $\mathrm{pH}$-Abfall von 0,100 und stimmt mit den Daten von Winters \& Dell (7) gut überein. Diese Autoren fanden ein $\Delta\left[\mathrm{H}^{+}\right]$von $0,74 \mu \mathrm{mol}$ für ein $\Delta \mathrm{pH}$ von 0,100 , wobei ein Hämatokrit von $0,451 / 1$ angenommen wurde. Prüften wir die Pufferkapazität der reinen Substratemulsion, ergaben sich Werte von $0,85 \pm 0,008 \mu \mathrm{mol} \mathrm{H}{ }^{+}$für den genannten $\mathrm{pH}$-Abfall. Der Anteil des Serums an der Gesamtpufferkapazität beträgt somit 47\%, derjenige der Substratemulsion 53\%.

Die Pufferkapazität des einzelnen Ansatzes wird dadurch prüfbar, daß der $\mathrm{pH}-\mathrm{Abfall}$ im Testansatz nach Zugabe von $2 \mu \mathrm{mol}$ Salzsäure gemessen wird. Eine veränderte Pufferkapazität aufgrund erheblich abweichender Proteinkonzentration in dem zu analysierenden Serum kann mit diesem - der Verwendung eines ,,internen Standards" analogen - Verfahren erkannt und evtl. korrigiert werden. Sind Proteingehält der Probe bzw. Pufferkapazität des gesamten Ansatzes nicht bekannt, so können keine exakten Ergebnisse erwartet werden.

Die enzymatische Hydrolyse des Trioleins zeigt zwischen pH 9,0 und 8,5 ein Plateau (4). Auch der gemessene $\mathrm{pH}$-Abfall verläuft in dem genannten Bereich aufgrund der Puffercharakteristik der Substratemulsion und der Serumproteine geradlinig. Als Ursache dieser linearen Pufferung wird in bezug auf die Proteine die Uberlagerung von Komponenten mit unterschiedlichen $\mathrm{pK}$-Wertèn angenommen (7); der gleiche Mechanismus ist für die Makromolèküle zu diskutieren, aus denen Gummi arabicum zusammengesetzt ist.

Vergleichsuntersuchungen mit dem kontinuierlichen titrimetrischen Test ergaben eine befriedigende Uberein: stimmung. Mithin stellt das hier beschriebene Verfahren eine Alternative für diejenigen Laboratorien dar, die nicht über die Mittel zur Beschaffung der für diè pH-StatTechnik notwendigen Titrationsanlage verfügèn. Im Einzelfall sind die diskutierten Fehlerquellen durch unterschiedlichen Proteingehalt der Seren zu berücksichtigen. Der Zeitaufwand bei der technischen Ausfuihrung ist gegenüber dem Titrationsverfahren nur geringfügig redu: ziert. Die Notwendigkeit, hochaktive Pröben mit inakti. viertem Sammelserum zu verdünnen und die Tatsache, daß nur Serum analysiert weîden kann, bedeuten einen Nachteil gegenüber dem titrimetrischen Test.

\section{Schätzung des pH-Abfalls}

Der $\mathrm{pH}$-Abfall einer mit Serum versetzten Olivenölemulsion stellt auch die Grundlage des von Härtel et al. (1) beschriebenen Suchtests dar. Dabei wird die Farbänderung von $m$-Kresolpurpur, dessen pK-Wert bei 8,32 liegt, im $\mathrm{pH}$ :Bereich zwischen etwa 8,3 und 7,4 ermittelt. Die Kalibrierung der von Hörtel et al. (1) angegebenen Farbskala erfolgte mit Seren, deren kațalytișche Aktivität im titrimetrischen Test bestimmt wurde. Dem geübten Untersucher ist es möglich, mit dem Verfahren zu reproduzierbaren Ergebnissen zu kommen. " :

Es sei ausdrücklich darauf hingewiesen, daß die hier be: schriebenen Untersuchungen mit der auch im titrimetrischen Test verwendeten Triolein-Emulsion in Anwesenheit von Natriumglykocholat ausgeführt wurden. Die von uns verwendete Indikator-haltige Substratemulsion enthält - abweichend von der Vorschrift nach Härtel et al. (1) - Natriumglykocholat in einer Konzentration von $0,83 \mathrm{mmol} / \mathrm{l}$. Nach Serumzugabe entspricht die Gallensalzkonzentration mit $0,75 \mathrm{mmol} / 1$ derjenigen im kontinuierlichen titrimetrischen Test (4). Die Substratkonzentration liegt mit $0,1771 / 1$ höher als beim Titrationsverfahren $(0,1331 / 1)(3)$. Die größere Viskosität des Ansatzes ist für den Farbtest deshalb günstig, da das Schütteln erschwert ist und somit der durch das Kohlendioxid der Raumluft bedingte $\mathrm{pH}-\mathrm{Abfall}$ in einer 2-3 mm dicken Schicht àn der Oberfläche des Ansatzes bei vorsichtiger Handhabung keine Fehlerquelle darstellt. Die enzymatische Hydrolyse des Trioleins erfolgt, wie im kontinuierlichen titrimetrischen Test geżeiğt werden konnte (4), bei beiden Substratkonzentrationen praktisch mit gleicher Geschwindigkeit. Zur Brauchbarkeit verschiedener Chargen der Olivenölemulsion aus der Testpackung Merckognost Lipase kann von uns nicht Stellung gepiommen werden. 
Bei der Bewertung der von Härtel et al. (1) angegebenen Analytik ist zu beruicksichtigen, daß das Verfahren als Suchtest beschrieben wurde. Es erlaubt nur in Stufen von $20 \mathrm{U} / 1$ abzulesen; bei der Durchführung von Doppelbestimmungen ist eine Differenzierung bis zu $10 \mathrm{U} / 1$ möglich. Bei verkürzter Inkubationszeit können auch sehr hohe katalytische Aktivitäten bestimmt werden.

Wie bei der potentiometrischen Messung des pH-Abfalls stellt eine stark abweichende Proteinkonzentration der Probe eine Fehlerquelle dar. Weiterhin können nur farbtüchtige Untersucher mit der Ausführung des Verfahrens betraut werden.

In Vergleichsuntersuchungen mit dem kontinuierlichen titrimetrischen Test wurde eine für diagnostische Zwecke ausreichende Ubereinstimmung festgestellt. Bei niedrigen katalytischen Aktivitäten sind der pH-Abfall und somit die Farbänderung des Ansatzes nur sehr gering, so daß bei einer nur stufenweise möglichen Abschätzung im Einzelfall relativ große Differenzen zu dem Titrationsverfahren unvermeidbar sind. An 59 Seren mit einer katalytischen Aktivität von unter $100 \mathrm{U} / 1$ wurden mit dem Suchtest jedoch ausschließlich Ergebnisse ermittelt, die im Normbereich (bis $160 \mathrm{U} / \mathrm{l}$ ) lagen, so daß auch diese

\section{Literatur}

1. Härtel, A., Banauch, D. \& Helger, R. (1971) Z. Klin. Chem. Klin. Biochem. 9, 396-397.

2. Rick, W. (1976) Lipase. In: Handbuch der Inneren Medizin (Forell, M. M. ed.). 5. Aufl. Bd. III/6: Pankreas. Springer, Berlin pp. 350-361.

3. Rick, W. (1969) Z. Klin. Chem. Klin. Biochem: 7, 530-539.

4. Hockeborn, M. \& Rick, W. (1982) J. Clin. Chem. Clin. Biochem. 20, 773-785.

5. Helger, R. (1982) persönliche Mitteilung. niedrigen Aktivitäten zuverlässig einzuordnen sind. Die größten Abweichungen betrugen bei Werten von $67 \mathrm{bzw}$. $82 \mathrm{U} / \mathrm{l} \mathrm{im}$ titrimetrischen Test +23 bzw. -32 U/1. Höhere Lipaseaktivitäten führen zu einer stärkeren Farbänderung mit der Zeiteinheit, somit wird die bessere Korrelation bei Seren mit Werten oberhalb des Normbereichs verständlich.

Trotz der durch langjährige Úbung erzielten guten Ǔbereinstimmung mit den Ergebnissen der Titration kann der Test keinesfalls - wie kürzlich beschrieben (8) - als Referenzmethode für andere Verfahren dienen. Neben der Anwendung im Bereitschaftsdienst - hier liegt ohne apparativen Aufwand innerhalb kurzer Zeit ein diagnostischer Hinweis vor - ist der Test vor allem dazu geeignet, Seren mit im Normbereich liegender Lipase sicher zu erkennen. In diesen Fällen ist es vertretbar, als Befund „Lipaseaktivität im Normbereich" mitzuteilen. Wenn anschließend nur die als sicher oder fraglich pathologisch identifizierten Seren im kontinuierlichen titrimetrischen Test analysiert werden, hält sich der Arbeitsaufwand in vertretbaren Grenzen. Beim Einsatz der beiden genannten Lipase-Bestimmungsverfahren ist die Zuverlässigkeit der Ergebnisse gesichert.
6. Chance, B. \& Nishimura, M. (1967) Sensitive Measurements of Changes of Hydrogen Ion Concentration. In: Methods in Enzymology (Estabrook, R. W. \& Pullman, M. E. eds.). Vol. X. Academic Press, New York pp. 641-650.

7. Winters, R. W. \& Dell, R. B. (1965) Regulation of Acid-Base Equilibrium. In: Physiological Controls and Regulations (Yamamoto, W. S. \& Brobeck, J. R. eds.). Saunders, London pp. 181-238.

8. Lorentz, K. \& Flatter, B. (1980) Med. Lab. 33, 236-239.
Prof. Dr. W. Rick

Institut für Klinische Chemie und Laboratoriumsdiagnostik der Universität Düsseldorf Moorenstraße 5 D-4000 Düsseldorf 
